\title{
Implementing Cooperative Learning in Intensive Reading Course for Chinese Learners of English
}

\author{
CHEN Long \\ Jinan University, Guangzhou, China
}

\begin{abstract}
Studies on Cooperative Learning (CL) have demonstrated advantages and effectiveness of employing strategies of CL on English as a Second Language (ESL). This report presents the processes of CL implemented in two English intensive reading courses at a Chinese university. The purpose is to arouse the students' awareness of working in groups in their English reading classroom and to enhance their reading comprehension at tertiary level. The results show that students can adapt to small group work when they realize the benefits brought to them. Although positive effectiveness of CL is prevalent at any levels in educational contexts, benefits of CL on ESL are not deeply cultivated as expected, particularly for Chinese learners of English and some problems can also be found in implementing CL. As the emphasis of curriculum of English Language Teaching (ELT) in China has been on developing students' competence in communication in English, it is necessary for teachers to adopt CL in classroom instructions rather than teacher-centered approaches.
\end{abstract}

Keywords: Cooperative Learning (CL), English intensive reading, English majors, procedures of implementation, issues

\section{Introduction}

Teachers hope that the class can be homogeneous and the students actively participate in the activities in second language classroom. But in reality, when "walking into a typical ESL classroom and you will observe a familiar situation where interaction in the classroom is dominated by the teacher, with the students mainly responding to the teacher's initiatives" (Richards \& Renandya, 2002, p. 49). In order to manage classroom activities dynamically, instructors and researchers start to implement Cooperative Learning (CL) since it can "lead to a more dynamic classroom interaction that promotes more learning" (Richards \& Renandya, 2002, p. 49).

$\mathrm{CL}$ is widely advocated by many educators in different disciplines at various levels. As the development of educational theories regarding behavioral, developmental, and social interdependence, "cooperative learning has become a well-documented philosophy of classroom instruction encompassing many strategies" (Thanh, 2014, p. 11). Although many studies have been generally positive about the learning effects of CL (Cullen, Kullman, \& Wild, 2013), there are not so many studies on tertiary language teaching and learning in China. English language learning achievement is not very satisfactory for Chinese learners although most Chinese university students have been learning English for over 10 years. This report presents the findings in the experiments with English major students at a Chinese university employing cooperative learning approaches.

CHEN Long, associate professor, Ph.D., College of Foreign Studies, Jinan University. 
The participants of the study are first-year and second-year students by the time when the experiments are designed. In the process of the experiment, the researcher of the project adapts and devises procedures by integrating small group work into classroom teaching in intensive English reading course. The results of the two study cases demonstrate that Chinese university students prefer to use effective cooperative strategies once they are motivated to work cooperatively even though they are used to traditional approaches before. But some problems occur as well for Chinese learners of English when implementing CL in classroom. It needs the researchers to work more deeply and thoroughly on the issues found in the study.

\section{Cooperative Learning on English as a Second Language}

On the basis of D. W. Johnson and R. T. Johnson's (1999) five components of CL, namely (1) Positive interdependence, (2) Individual accountability, (3) Face to face promotive interaction, (4) Social skills, and (5) Group processing, researchers have found that cooperative learning strategies help achieve the goal of second language acquisition (DelliCarpini, 2009). Along with the implementations of CL for students at any levels, "it has emerged as a significant concept and instructional practice in the field of second language education" (Liang, Mohan, \& Early, 1998, p. 13).

Since the findings have shown the effects and benefits of CL, numerous studies can be found on English as a Second Language (ESL), but the major concerns are about the advantages of cooperative learning strategies, building sense of efficacy, forming heterogeneous groups in ESL classroom, and delivering effective ESL instruction. Ning (2011) claims that CL is superior to the teacher-fronted instruction especially in speaking, listening, and reading after examining the use of group formation, technique adaptation, and course evaluation for Chinese university students. DelliCarpini (2009) finds that effective cooperative learning models help pre-service teachers build a sense of efficacy. Lotan (2008) suggests that the instructors must take the students' language proficiency into consideration when organizing group work. Jacobs and Hall (2002) discuss the necessity of delivering effective instruction and claim that $\mathrm{CL}$ is more than just putting students in groups and giving them something to do. "Cooperative learning principles and techniques are tools which teachers use to encourage mutual helpfulness in the groups and the active participation of all members" (Jacobs \& Hall, 2002, p. 52). Although the findings of CL on ESL demonstrate the effects and benefits for second language learning and teaching, there are few studies on the processes of implementing CL in the ESL classroom diachronically and consecutively. The following section displays the procedures of the implementation of CL in two English intensive reading courses for Chinese university students so as to demonstrate the consequences of implementing $\mathrm{CL}$ in second language classroom.

\section{Cooperative Learning in English Intensive Reading Course}

Since the studies of CL have demonstrated that this method is beneficial to students' learning at any levels, the teacher would like to apply cooperative learning approaches in teaching of two English intensive reading courses in summer semester of 2014 at a Chinese university. These two courses are Comprehensive English II and Comprehensive English IV. The participants of Comprehensive English II course are first-year English major students while second-year English major students attend Comprehensive English IV. Both courses are a four-hour session each week for 18 weeks. Altogether 36 students from two classes contribute to the activities of CL. Seventeen first-year students attend Comprehensive English II and 19 second-year students come to Comprehensive English IV. First-year students' English proficiency level is considered low as required by the 
curriculum. They are classified into the group of beginners of English learners. Nineteen second-year students are considered as the intermediate level of learners since they have been learning English at the university for over one year when the experiment started and their level is higher than that of the first-year students. Therefore, the proficiency level of students of Comprehensive English II and Comprehensive English IV is different. In the following part of the paper, the procedures of implementing CL for both classes are described so that the benefits of using this method for language learners can be realized as well.

The basis for the instructional approach used in these two courses is the cooperative learning strategies proposed by D. W. Johnson and R. T. Johnson (1999). The participants of each course are divided into groups of three or four. Homework assignments are distributed to teams of three or four students that remain together every four weeks for a semester. The teacher also designs out-of-class exercises because they are supplementary to in-class group activities. The out-of-class activities are done by fixed team groups.

\section{Day 1, Week 1}

On the first day of the summer semester of 2014, the teacher informed the students that they would adopt cooperative learning approaches to work on English intensive reading courses. The students from both classes at first did not have any ideas about CL. The teacher explained the methods and demonstrated how the students would work cooperatively on the materials they were going to discuss.

The teacher spent some time explaining to the students why cooperative learning strategies would be adopted in intensive reading courses rather than continue the traditional methods. The students were assured that application of CL was a challenge for the teacher as well because the teacher wanted to introduce more effective and beneficial teaching and learning strategies to the students. The teacher told them that educational research indicated that students learn better and get higher grades by working in small groups and teaching one another some of the time rather than listening to instructors lecture all of the time (see DelliCarpini, 2009; Felder \& Brent, 1994; Gagné \& Parks, 2013; Ghaith \& Yaghi, 1998; Gillies \& Boyle, 2010; D. W. Johnson \& R. T. Johnson, 1999; Naughton, 2006; Thanh, 2014; Webb, 2008). The teacher also explained that when they start to work in society in the future, they will be expected to work in teams. So they might as well start learning how to collaborate with others earlier, especially during university time because it is a critical period for students to understand the importance of team work and develop their ability to work for the future. When they do some team work in the courses, they have teachers and classmates to rely on for help. But once they are in society, they have to do everything by themselves; they normally do not have anyone to supervise them. Then it is very necessary to learn and develop such a kind of ability as early as possible so that they can conveniently adjust themselves in the future.

Table 1

Overview of the Course and Participants

\begin{tabular}{llll}
\hline Course title & Session hours per week & Student's level & Number of participants \\
\hline Comprehensive English II & 4 hours & Beginners (first-year students) & 17 \\
Comprehensive English IV & 4 hours & Intermediate (second-year students) & 19 \\
\hline
\end{tabular}

After explanation of CL, the students were divided into groups with three or four participants in each group. In Comprehensive English II class, five groups were formed, three groups with three members and four students for two groups. In Comprehensive English IV, the teacher constructed four groups of four students and one group with three team members. There were also five groups in this course. The group division was done 
by the teacher although the students wanted to work with those that they were familiar with. In order to make the groups heterogeneous, the teacher selected the students and assigned them into groups instead of allowing them to form groups by their choice. Table 1 shows the general information of the students and the courses.

On the first day, the teacher did not only tell the students the new method they were going to employ for the two courses and the advantages of employing this method, the teacher also told them that all homework assignments had to be done in fixed groups with one solution set submitted per group. It is very different from the traditional homework. The teacher clearly illustrated the rules for group formation, and specified individual roles within groups, one coordinator, one recorder, and one or two checkers, with the roles rotating on each assignment.

Because the two courses are scheduled consecutively, the discussion of the activities by two classes is put together in this section rather than describing them separately. When one class finishes, another starts. That means each time when the teacher meets the students, the teacher works in turn with these two classes for four hours. For the whole week, it is an eight-hour session for both levels of students. This also provides the teacher opportunities to adjust the implementation of CL immediately when the teacher realizes some problems.

\section{Day 2, Week 1}

This is the actual time that the teacher starts to implement CL for intensive English reading courses. Since the groups were formed and all participants found their group members, the teacher organized the small group problem-solving activities concerning words, phrases, sentences, paragraphs, and texts during the sessions. The level of interaction varied on the basis of the time management of each group. Some groups could finish doing the exercises much faster than the other groups.

The second day of comprehensive English reading courses at first experienced a little difficulty because the students did not have very clear idea of how to cooperate and interact in the groups. Most students still worked alone by themselves as they had the habit of working independently. When the session was almost coming to an end, the teacher proposed some suggestions for improving interaction in the groups on the basis of the teacher's observation on the group activities. By the end of the second day of both courses, the first homework was assigned although some problems occurred on the real day of CL.

\section{First Homework Assignment}

When the first homework was assigned to the student groups, they were instructed that they had to submit their assignments in groups. Some group members did not know very clearly how to work in groups on the assignment. Some of them would like to do the assignment first individually and later joined the group work. Some students even asked for doing the assignments individually. Taking such a kind of situation into consideration, the teacher allowed two students first did the assignments by themselves and then joined the groups when they felt that they could work cooperatively with others later on since no individual assignments would be accepted after the second assignment.

\section{First Four Weeks}

During the first four weeks, the teacher organized in-class activities such as problem-solving, think-pair-share, trouble-shooting, brainstorming, and question generation proposed by Felder and Brent (1994). In each session, the teacher observed their interaction and generally encouraged the students to work in their groups with questions and activities provided. Sometimes the teacher made small adjustments and rearranged 
the groups to let those students who did not work with others. This new arrangement in class time offered the students opportunity to work with those who they did not work together before. This rearrangement in class was just temporary and happened occasionally; the students should always stay with their original groups especially when they did homework assignments. As the teacher realized that temporary rearrangement was efficient for group work, the teacher decided to change group members after four weeks. Then new groups were formed by the end of four weeks. This group rotation happened every four weeks and continued to the end of the semester.

In the first four weeks, after every four-hour session, the teacher tested the students' comprehension on the text they had learned. At the same time, the teacher used the test to check the language points that the students needed to work more on. The students made obvious progress on each test. The scores of weekly test are presented in Table 2.

Table 2

Average Scores per Week of Both Classes

\begin{tabular}{lll}
\hline Weeks & \multicolumn{2}{c}{ Average scores (100 points) } \\
\cline { 2 - 3 } & Beginners $(\mathrm{N}=17)$ & Intermediate $(\mathrm{N}=19)$ \\
\hline Week 1 & 72.6 & 69.1 \\
Week 2 & 78.8 & 76.8 \\
Week 3 & 83.5 & 80.5 \\
Week 4 & 85.7 & 83.6 \\
\hline
\end{tabular}

The average score of the first-year students was 72.6, and 69.1 for the second-year students on the test of the first week. By the end of the fourth week of cooperating, the average score of beginners increased to 85.7 and 83.6 for the intermediate students.

Table 2 clearly shows that the increasing tendency of the students' score on the test each week is very obvious. The students were not worried about tests any more but interacted more cooperatively because they knew that the score of each team represented the group's reputation as well.

\section{End of Eight Weeks}

By the end of eight weeks, the students can easily and conveniently interact with group members. The students are getting used to group work and rotating their roles in groups. This also enhances the cooperation and team work for group members. After learning cooperatively for eight weeks, as it is in the middle of the semester, the teacher did a mid-term evaluation to find out how small group work was going among the students. The teacher evaluated students' group work on the basis of five criteria proposed by D. W. Johnson and R. T. Johnson (1999). The results of the students' evaluation on the employment of CL show that the students are positive about group work. They have developed the habit of working cooperatively rather than working individually. They think that CL is helpful and beneficial in their learning not only in intensive reading course, but also in other courses they attend. Therefore, that is why the more group work the students do, the more effective they think the method is for them.

\section{End of the Semester}

In the remaining time of the semester, CL goes on smoothly until the end of the semester. By the end of both courses, the final evaluation is given in written test. The students' scores show that the final grade distribution in the two courses is different from the courses previously instructed with traditional approaches. 
By comparing with the traditional methods used before, the students score on reading course increased dramatically. Table 3 demonstrates the difference of students' scores in using CL and traditional techniques.

Table 3

Score Difference Before and After Using CL, Beginner $N=17$, Intermediate $N=19$

\begin{tabular}{lllll}
\hline Score range & \multicolumn{2}{c}{ Before CL (\%) } & \multicolumn{2}{c}{ After CL (\%) } \\
\cline { 2 - 5 } & Beginners & Intermediate & Beginners & Intermediate \\
\hline$\geq 90$ & 0 & 10.5 & 11.8 & 42.1 \\
$80-89$ & 35.3 & 47.4 & 58.8 & 57.9 \\
$70-79$ & 35.3 & 36.8 & 17.6 & 0 \\
$60-69$ & 29.4 & 5.3 & 11.8 & 0 \\
\hline
\end{tabular}

From Table 3, both beginners and intermediate students' scores show the increasing tendency after employing CL. Compared to $0 \%$ of students getting over 90 for beginners when using traditional methods, $11.8 \%$ of them earned over 90 after employing CL. The percentage of getting 90 increased most for intermediate level from $10.5 \%$ to $42.1 \%$. The tendency clearly shows the benefits of using CL in the reading course. The success of implementing CL in intensive English reading course indicates that CL leads to improved learning in all but the least qualified and most poorly motivated students (Felder \& Brent, 1994).

Although the benefits of CL are clearly demonstrated in the experiment, no method can be perfect. When the teacher realizes the benefits and effects of CL, some problems of implementing this approach should not be neglected. In the following section, the issues and problems in implementing CL are presented and some solutions to the problems are discussed.

\section{Issues Raised in the Experiments}

The findings of the experiment prove the effectiveness of the method proposed by researchers such as Thanh (2014), DelliCarpini (2009), Webb (2008), Gagné and Parks (2013), Ghaith and Yaghi (1998), Naughton (2006), Gillies and Boyle (2010). Although the employment of the CL for these two different classes is successful to a certain extent, there are still some issues and problems in the process of utilizing the method. The followings are some problems raised in the experiment the whole semester.

(1) The students lack knowledge of CL. When the students attended the university, they had been learning at the school for over 12 years. During these years of learning, rote-learning is the major method they are familiar with. When the cooperative learning method is introduced to them, it is the second semester of the school year for beginners and the fourth semester for intermediate students. They find it is a little difficult for them to implement a method which is completely different from the traditional ones. Even when they are trained with the method, they are still not very confident in cooperating with peers. They are worried if everything is going well in their group. They are afraid that once the group work is not very highly appraised by the instructor, their work will be ended in failure.

(2) The students meet the instructor's needs intentionally. This problem found in the experiment is mainly caused by their familiarity with the instructor. When the CL is decided to use in both classes, the instructor has taught comprehensive English I for beginners for one semester and comprehensive I, II, III for intermediate students for three semesters. When CL is introduced, they also know that the instructor wants to do an experiment with the new method. They are very helpful and cooperative in doing this experiment. They think that they should try their best to meet the instructor's needs for the course. Then sometimes, when they work in 
their groups they try to do the tasks cooperatively even though they encounter some difficulties. The reason that arouses the problem can be that Chinese students normally do not challenge the instructor's authority. They have to show their respect to their teachers and cheer their teachers. They even hide their true feelings when working under the guidance of the teacher. Normally the problem like this will not be observed by the instructor when the students work in their groups. As one student said to the instructor, "We like your class, but sometimes we have difficulties. We do not want to disappoint you. We try to work together actively."

(3) Although CL is implemented smoothly for 18 weeks, "hitchhikers" are frequently observed in the students' group work, especially in out-of-class activities. When some students do not have time and/or opportunity to work together after class, they choose a good student to represent them even though they contribute their ideas to the group. This makes the weak students hitchhike the group work and get the same score as the good students on their group assignments.

(4) There is an imbalance between out-of-class activities and in-class activities. The instructor cannot monitor the students' out-of-class activities because they have to deal with many other homework assignments at the same time and their schedule is different. Students think that they should use class time more efficiently rather than trying to find meeting time after the class. They even suggest that the instructor assign individual work after class and accept individual assignments. Although the instructor also tries to coordinate their out-of-class group work, it seems that they cannot come to a compromise for all group participants, especially meeting time out of the class. The imbalance of in-class activities and out-of-class group work exists throughout the whole semester.

\section{Conclusion}

The study of implementing CL for English reading courses demonstrates that the Chinese students are normally not used to CL but once they are trained they can achieve the goal of this method. From the experiments, the results show that CL helps students broaden their view with language knowledge and motivate the learners' autonomy. They develop their interpersonal skills and social ability to work together as well.

Although CL is beneficial in intensive English reading courses, there are still some problems raised in the study. The results of the study show that the students sometimes are skeptical in employing CL in their group work. They also sometimes intentionally cheer up the instructor as they want to help the instructor to achieve the set-goal of the study. This makes the study sometimes a little deviant from the original purpose. Although group work can enhance students' participation in the activities, "hitchhiker" is a problem that needs to be solved as the situation indicates that the learners prefer to have in-class activities rather than out-of-class group work. This also demonstrates that out-of-class group activities are not as effective as other methods carried out in the classroom. After all, CL makes the students realize that language learning can be effectively done by working with others and also benefit themselves. Although some problems exist, CL is superior to teacher-centered method to a certain extent.

\section{References}

Cullen, R., Kullman, J., \& Wild, C. (2013). Online collaborative leaning on an ESL teacher education programme. ELT Journal, 67(4), 425-434.

DelliCarpini, M. (2009). Enhancing cooperative learning in TESOL teacher education. ELT Journal, 63(1), 42-50.

Felder, R., \& Brent, R. (1994). Cooperative learning in technical courses: Procedures, pitfalls, and payoffs. Retrieved from http://www2.ncsu.edu/effective_teaching/ 
Gagné, N., \& Parks, S. (2013). Cooperative learning tasks in a Grade 6 intensive ESL class: Role of scaffolding. Language Teaching Research, 17(2), 188-209.

Ghaith, G. M., \& Yaghi, H. M. (1998). Effect of cooperative learning on the acquisition of second language rules and mechanics. System, 26, 223-234.

Gillies, R. M., \& Boyle, M. (2010). Teachers' reflections on cooperative learning: Issues of implementation. Teaching and Teacher Education, 26, 933-940.

Jacobs, G., \& Hall, S. (2002). Implementing cooperative learning. In J. C. Richards \& W. A. Renandya (Eds.), Methodology in language teaching: An anthology of current practice (pp. 52-58). Cambridge: Cambridge University Press.

Johnson, D. W., \& Johnson, R. T. (1999). Making cooperative learning work. Theory into Practice, 38(2), 67-73.

Liang, X., Mohan, B. A., \& Early, M. (1998). Issues of cooperative learning in ESL classes: A literature review. TESL Canada Journal, 15(2), 13-23.

Lotan, R. A. (2008). Developing language and mastering content in heterogeneous classrooms. In R. M. Gillies, A. F. Ashman, \& J. Terwel (Eds.), The teacher's role in implementing cooperative learning in the classroom (pp. 184-200). New York: Springer Science + Business Media.

Naughton, D. (2006). Cooperative strategy training and oral interaction: Enhancing small group communication in the language classroom. The Modern Language Journal, 90(2), 169-184.

Ning, H. (2011). Adapting cooperative learning intertiary ELT. ELT Journal, 65(1), 60-70.

Richards, J. C., \& Renandya, W. A. (Eds). (2002). Methodology in language teaching: An anthology of current practice. Cambridge: Cambridge University Press.

Thanh, P. T. H. (2014). Implementing cross-culture pedagogies, education in the Asia-Pacific region: Issues, concerns and prospects 25. Dordrecht: Springer Science + Business Media.

Webb, N. M. (2008). Teacher practices and small-group dynamics in cooperative learning classrooms. In R. M. Gillies, A. F. Ashman, \& J. Terwel (Eds.), The teacher's role in implementing cooperative learning in the classroom (pp. 201-221). New York: Springer Science + Business Media. 